Appleyard, G. \& Woods, D. D. (1956). J. gen. Microbiol. 14, 351-365

\title{
The Pathway of Creatine Catabolism by Pseudomonas ovalis
}

\author{
By G. APPLEYARD and D. D. WOODS \\ Microbiology Unit, Department of Biochemistry, University of Oxford
}

SUMMARY : Creatine is oxidized by suspensions of a strain of Pseudomonas ovalis Chester harvested from media containing creatine as main source of carbon and nitrogen. A possible pathway of degradation of at least part of the creatine is: (a) hydrolysis of creatine to sarcosine and urea, $(b)$ oxidation of sarcosine to glycine and formaldehyde, (c) oxidation of the latter products to $\mathrm{CO}_{2}$ and $\mathrm{NH}_{3}$ with considerable concurrent oxidative assimilation.

Soluble enzyme preparations catalysing stage $(a)$ were obtained by aqueous extraction of either acetone-dried or toluene-treated organisms. The enzyme for stage $(b)$ was present in the insoluble residue from the latter organisms.

The literature concerning micro-organisms able to grow with creatine or creatinine as sole source of carbon and nitrogen has been surveyed by NimmoSmith \& Appleyard (1956). The ability of such organisms to grow on related compounds or derivatives (or to metabolize them in cell suspension) may give indirect evidence as to possible pathways of creatine metabolism. A compound which is not utilized is unlikely (unless unable to enter the organism) to be an intermediate; conversely, a compound which is rapidly attacked may be, but is not necessarily, on the pathway. On these grounds possible intermediates in the degradation of creatine by various micro-organisms are creatinine, sarcosine, glycocyamine and methylguanidine (Table 1); it may be noted that with no organism is sarcosine excluded. Glycocyamine and methylguanidine appear as 'possible' with some organisms but 'unlikely' with others.

Table 1. Specificity of organisms able to grow on creatine

\begin{tabular}{|c|c|c|c|}
\hline \multirow[b]{2}{*}{ Organism } & \multicolumn{2}{|c|}{ Related compounds which } & \multirow[b]{2}{*}{ Reference } \\
\hline & Support growth & $\begin{array}{l}\text { Do not support } \\
\text { growth }\end{array}$ & \\
\hline ' $\mathbf{H R}$ ' & - & $\begin{array}{l}\text { Glycocyamine, } \\
\text { methylguanidine }\end{array}$ & (1) \\
\hline $\begin{array}{l}\text { 'NC' (Corynebacterium } \\
\text { creatinovorans) }\end{array}$ & $\begin{array}{l}\text { Creatinine, methyl- } \\
\text { guanidine, glyco- } \\
\text { cyamine, sarcosine }\end{array}$ & - & (1) \\
\hline A bacterium & Creatinine & 一 & (2) \\
\hline$\Lambda$ mould & 一 & Glycocyamine & (3) \\
\hline Pseudomonas ovalis & $\begin{array}{l}\text { Glycocyamine, } \\
\text { sarcosine }\end{array}$ & - & (4) \\
\hline$P$. aeruginosa & Sarcosine & Glycocyamine & (5) \\
\hline
\end{tabular}

References: (1) Dubos \& Miller (1937); (2) Beard (1943); (3) Beard (1944); (4) Roche, Girard, Lacombe \& Mourgue (1948); (5) Kopper (1947). 
A more extensive study of creatinine and creatine catabolism has been made with a strain of Pseudomonas aeruginosa which grows well on a medium containing either of these substances (Kopper \& Beard, 1947; Kopper, 1948). Creatinine was first converted to creatine; since suspensions of organisms oxidized sarcosine the next step was thought to be the hydrolysis of creatine to sarcosine and urea, but no direct evidence for this reaction was found. The breakdown of sarcosine by this organism was also studied (Kopper \& Robin, 1950; Kopper, 1950); this work will be discussed later.

The organism used in the present work was a strain of Pseudomonas ovalis Chester isolated by Nimmo-Smith (1949). It degrades creatine, but unlike the other organisms referred to above, does not attack creatinine. It was shown in the preceding paper (Nimmo-Smith \& Appleyard, 1956) that suspensions of organisms harvested from a medium containing creatine oxidized this substance with overall formation of urea, $\mathrm{NH}_{3}$ and $\mathrm{CO}_{2}$. Quantitatively the values for $\mathrm{O}_{2}, \mathrm{CO}_{2}$ and $\mathrm{NH}_{3}$ were only 45,50 and $70 \%$, respectively, of those expected for the reaction (1) below, but there was evidence that these low values were due, at least in part, to oxidative assimilation; the yield of urea was theoretical:

$$
\mathrm{NH}_{2} \cdot \mathrm{C}(=\mathrm{NH}) \cdot \mathrm{N}\left(\mathrm{CH}_{3}\right) \cdot \mathrm{CH}_{2} \cdot \mathrm{COOH}+3 \mathrm{O}_{2}=\mathrm{CO}\left(\mathrm{NH}_{2}\right)_{2}+\mathrm{NH}_{3}+3 \mathrm{CO}_{2}+\mathrm{H}_{2} \mathrm{O} \text {. }
$$

A more detailed study of the course of this reaction with whole organisms and enzyme preparations is the subject of the present paper. Some of the results were briefly reported by Appleyard (1951).

\section{METHODS}

\section{Organisms}

Pseudomonas ovalis Chester (National Collection of Type Cultures, no. 7914). The isolation and maintenance of this organism and the preparation of suspensions after growth on a medium containing creatine are described by Nimmo-Smith \& Appleyard (1956).

Organism ' $S$ '. A contaminant found growing at refrigerator temperature in a solution of sarcosine $(0.033 \mathrm{M})$ was isolated; it appeared to be a pseudomonad but was not further characterized. The organism grew moderately on a medium similar to that used for Pseudomonas ovalis, but containing sarcosine ( $5 \mathrm{~g} . / \mathrm{l}$.) in place of creatine; there was no growth on creatine. Suspensions of this organism, prepared as above, were used for the assay of sarcosine.

\section{Preparations of organisms}

Acetone-dried organisms. A suspension of organisms (50 mg. dry wt./ml.) was mixed with cold acetone (10 vol.) and centrifuged. The deposit was washed three times on the centrifuge with 4 vol. quantities of acetone and finally stored in vacuo at $4^{\circ}$. This preparation hydrolysed creatine to sarcosine and urea and retained its activity for more than three months. 
At least $90 \%$ of the enzyme was obtained in solution by suspending the dried organisms in $0.02 \mathrm{M}$-phosphate buffer $(\mathrm{pH} 7$ ) and removing the insoluble residue by centrifuging. This extract was used for most experiments.

Toluene-treated organisms. A suspension of organisms $(10 \mathrm{ml}$.; $10 \mathrm{mg}$. dry wt. $/ \mathrm{ml}$.) was shaken with toluene $(1 \mathrm{ml}$.) for $10 \mathrm{~min}$. After centrifuging, the organisms were washed once with water $(10 \mathrm{ml}$.) and finally suspended in $10 \mathrm{ml}$. water. Activity was retained for at least $24 \mathrm{hr}$., though the preparation was normally used immediately.

Crushed organisms. The principle of Curran \& Evans (1942) was used. Cylindrical bottles $(30 \mathrm{ml}$.), containing $8 \mathrm{ml}$. organism suspension $(20 \mathrm{mg}$. dry wt./ml.), 10 g. glass balls (diameter $0.2 \mathrm{~mm}$.; Ballotini no. 13, Chance Bros., Smethwick) and $0.1 \mathrm{ml}$. tributyl citrate (anti-foam), were filled with $\mathrm{N}_{2}$ and shaken vertically at 400 oscillations $/ \mathrm{min}$. for $1 \mathrm{hr}$. at approximately $10^{\circ}$. The glass balls were removed by filtration.

\section{Estimations}

Uptake of $\mathrm{O}_{2}$ and formation of $\mathrm{CO}_{2}, \mathrm{NH}_{3}$ and urea were measured as described by Nimmo-Smith \& Appleyard (1956).

Creatine. The method of Eggleton, Elsden \& Gough (1943), as applied by Nimmo-Smith \& Appleyard (1956), was used. Sarcosine was found slightly to decrease the colour given by creatine, the percentage inhibition being proportional to the sarcosine concentration. In experiments in which sarcosine accumulated in the reaction mixture it was necessary therefore to apply a correction; this never exceeded $7 \%$.

Sarcosine. Suspensions of organism ' $\mathrm{S}$ ' oxidize sarcosine, glycine, formaldehyde and acetate, but not creatine or urea. Approximately 1.6 mole $\mathrm{O}_{2} /$ mole sarcosine were taken up and the uptake was strictly proportional to the amount of sarcosine added over the range tested (1-8 $\mu$ mole) (Fig. 1). It was possible to estimate sarcosine with an accuracy of $\pm 5 \%$ in reaction mixtures known not to contain other oxidizable substrates; this method was applied in experiments in which creatine was hydrolysed to sarcosine and urea by acetonedried organisms or by whole organisms anaerobically. Manometer vessels were set up containing $\mathrm{CO}_{2}$ absorbers, $1 \mathrm{ml}$. bacterial suspension ( $3 \mathrm{mg}$. dry wt. $/ \mathrm{ml}$.), $1 \mathrm{ml}$. phosphate buffer $(0 \cdot 2 \mathrm{M}, \mathrm{pH} 7 \cdot 8)$ and $1 \mathrm{ml}$. of either water (control), standard sarcosine or experimental sample (containing $2-8 \mu$ mole sarcosine). $\mathrm{O}_{2}$ uptake was measured at $30^{\circ}$ until it fell to the endogenous value (usually in 1-2 hr.).

Glycine. A microbiological assay with Leuconostoc mesenteroides $\mathbf{P 6 0}$ (American Type Culture Collection, no. 8042) was used. The technique was modified from that of Lascelles, Cross \& Woods (1954) for assay of serine only in that serine $\left(10^{-3} \mathrm{M}\right)$ was added to the medium and glycine omitted.

Formaldehyde. This was detected and estimated with an accuracy of $\pm 10 \%$ by its colour reaction with 1,8-dihydroxynaphthalene-3,6-disulphonic acid (chromotropic acid; MacFadyen, 1945). Methanol and formic acid do not react. 


\section{Chromatography}

Descending chromatograms were developed on Whatman no. 4 paper with either 'phenol' (a saturated solution of water in A.R. phenol) or 'butanol/ acetic acid' (the upper layer of a mixture of $n$-butanol, glacial acetic acid and water in the proportion of $4: 1: 5)$. The detecting agent was ninhydrin; sarcosine gives a positive reaction but the colour fades more rapidly than with most amino acids.

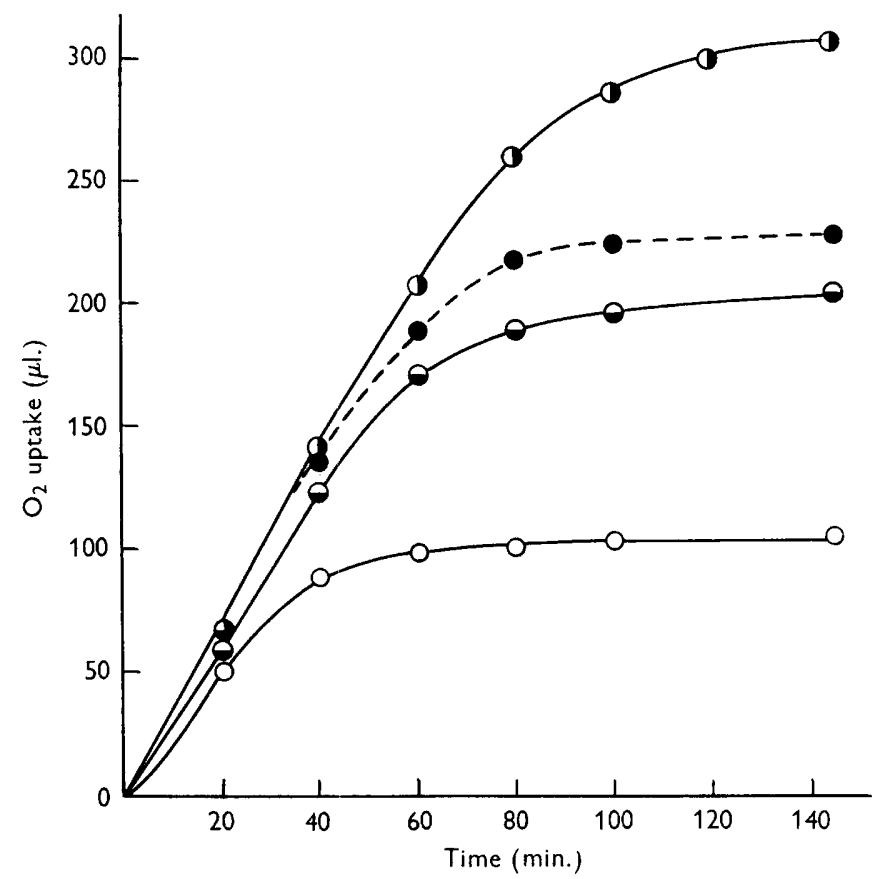

Fig. 1. Course of oxidation of sareosine by organism ' $S$ '. Organisms (3 mg. dry wt.) incubated in $0.067 \mathrm{M}$-phosphate buffer $\mathrm{pH} 7.8$ with $2.8(O), 5.6(\theta)$ and $8.3(0) \mu$ mole sarcosine or with a sample of an experimental product $(\bullet)$.

Glycine was detected and separated from other reaction products by chromatography on Dowex-50 resin (Moore \& Stein, 1951, as applied by Lascelles \& Woods, 1954).

\section{Experiments with suspensions of organisms}

In general, reaction mixtures were incubated at $30^{\circ}$ in Warburg manometers, either aerobically or anaerobically (in $\mathrm{N}_{2}$ ). The vessels contained cell suspension or enzyme preparation ( $1 \mathrm{ml}$.) and $0 \cdot 2 \mathrm{M}$-phosphate buffer $\mathrm{pH} 7 \cdot 8$ (1 $\mathrm{ml}$.) in the main compartment. Substrates $(0.5 \mathrm{ml} . ; 0.033 \mathrm{M}$ or as stated) were added from a side-bulb after equilibration. Reactions were stopped by the addition of $2 \mathrm{~N}-\mathrm{H}_{2} \mathrm{SO}_{4}\left(0.1 \mathrm{ml}\right.$.) or by heating to $100^{\circ}$ for $5 \mathrm{~min}$. The organisms were removed by centrifuging and estimations carried out with samples of the clear supernatant fluid. To avoid any loss of $\mathrm{NH}_{3}$ during manipulations a phosphate buffer of $\mathrm{pH} 7$ was used in the reaction mixture when $\mathrm{NH}_{3}$ was to be estimated. 


\section{RESULTS}

\section{Hydrolysis of creatine to sarcosine and urea}

Anaerobic action of whole organisms. Creatine disappeared slowly when incubated anaerobically with suspensions of Pseudomonas ovalis Chester. Urea was detected in the reaction products by the production of $\mathrm{NH}_{3}$ when further incubated with urease. Chromatography on paper showed the presence of a single ninhydrin-positive substance with an $R_{F}$ of 0.79 in 'phenol' and $\mathbf{0} \cdot 17$ in 'butanol/acetic acid'. The same $\boldsymbol{R}_{F}$ values were given by pure sarcosine and by samples from experiments in which sarcosine and urea had been incubated with suspensions. Samples from experiments in which organisms were incubated with creatine + sarcosine gave only one ninhydrin-positive spot corresponding to sarcosine.

Samples of the products also took up $\mathrm{O}_{2}$ when incubated with suspensions of organism ' $\mathrm{S}$ '; the time course of the oxidation was similar to that of sarcosine (Fig. 1).

Table 2. Hydrolysis of creatine by suspensions of Pseudomonas ovalis Chester anaerobically and by creatinase preparations

Creatine $(67 \cdot 1 \mu$ mole) incubated in $0.067 \mathrm{M}$-phosphate buffer $\mathrm{pH} 7 \cdot 8$ with either $(a)$ suspension of whole organisms (10 mg. dry wt.) in an atmosphere of $\mathrm{N}_{2}$, or $(b)$ creatinase (extract from $16 \mathrm{mg}$. acetone-dried organisms) in air. Total volume $6 \mathrm{ml}$. Controls incubated without creatine.

\begin{tabular}{lcccccc}
\multicolumn{5}{c}{$\mu$ mole (less control values) with } \\
& $\overbrace{1}^{\text {Whole organisms after (hr.) }}$ & \multicolumn{3}{c}{ Creatinase after (hr.) } \\
Creatine (removed) & $18 \cdot 4$ & $30 \cdot 1$ & $38 \cdot 1$ & $17 \cdot 2$ & $28 \cdot 3$ & $34 \cdot 1$ \\
Sarcosine (formed) & $16 \cdot 3$ & $29 \cdot 5$ & $36 \cdot 5$ & $16 \cdot 5$ & $26 \cdot 6$ & $33 \cdot 7$ \\
Urea (formed) & $15 \cdot 7$ & $29 \cdot 1$ & $37 \cdot 4$ & $15 \cdot 4$ & $27 \cdot 3$ & $33 \cdot 2$
\end{tabular}

Quantitative experiments showed the production of 1 mole each of sarcosine and urea for each mole of creatine decomposed (Table 2); no $\mathrm{CO}_{2}$ or $\mathrm{NH}_{3}$ was formed. The anaerobic reaction catalysed by the whole organisms is therefore:

$$
\mathrm{H}_{2} \mathrm{~N} \cdot \mathrm{C}(=\mathrm{NH}) \cdot \mathrm{N}\left(\mathrm{CH}_{3}\right) \cdot \mathrm{CH}_{2} \cdot \mathrm{COOH}+\mathrm{H}_{2} \mathrm{O}=\underset{\mathrm{CH}_{3}}{\mathrm{CO}\left(\mathrm{NH}_{2}\right)_{2}+} \cdot \mathrm{CH}_{2} \cdot \mathrm{COOH} .
$$

The rate of anaerobic removal of creatine at the final concentration normally used $\left(6 \times 10^{-3} \mathrm{M}\right)$ was only about $20 \%$ of the aerobic rate (Fig. 2). The addition of an equal quantity of sarcosine (which accumulates anaerobically) depressed the anaerobic rate byonly $10 \%$. The difference between the aerobic and anaerobic rates decreased with increasing concentration of creatine until, at $6 \times 10^{-2} \mathrm{M}$ (an almost saturated solution), they became almost equal (Fig. 2).

Action of acetone-dried organisms. Neither suspensions of acetone-dried organisms nor the soluble fraction extracted with phosphate buffer took up $\mathrm{O}_{2}$ in the presence of creatine. Both preparations catalysed the same reaction as whole organisms under anaerobic conditions, i.e. the quantitative hydrolysis 
of creatine to sarcosine and urea (Table 2). Suspensions of the dried organisms did not attack either sarcosine or urea, nor were they able to condense these two substances with formation of creatine. There was no action on creatine phosphate.

The enzyme which hydrolyses creatine to urea and sarcosine will be referred to as creatinase. The soluble preparation extracted from acetone-dried organisms was stable, though its activity was somewhat variable with different

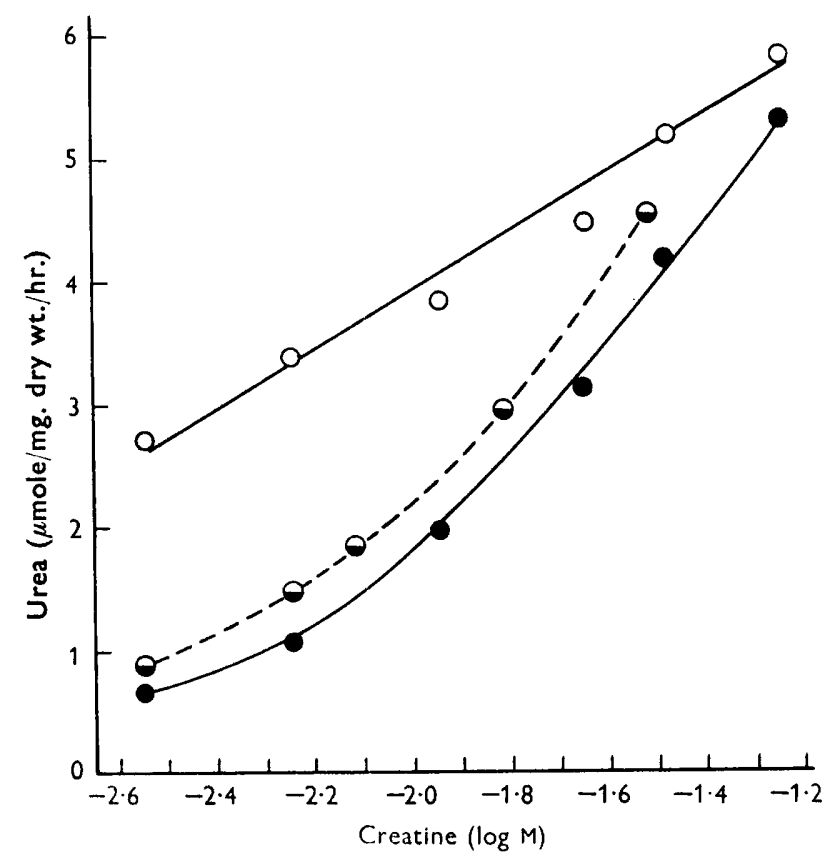

Fig. 2. Effect of substrate concentration on the hydrolysis of creatine by suspensions of Pseudomonas ovalis: aerobically $(O)$ or anaerobically in $\mathrm{N}_{2}(\bullet)$ and by a creatinase preparation aerobically $(\Theta)$. Hydrolysis followed by estimating urea produced after incubating whole organisms (5 mg. dry wt./ml.) or creatinase (extract from $6 \mathrm{mg}$. acetone-dried organisms $/ \mathrm{ml}$.) in $0.067 \mathrm{M}$-phosphate buffer $\mathrm{pH} 7 \cdot 8$ with the concentrations of creatine shown.

batches of original whole organisms. Under optimal conditions of $\mathrm{pH}(7 \cdot 8)$ and temperature $\left(30^{\circ}\right)$, and with an initial creatine concentration of $6 \times 10^{-3} \mathrm{M}$, the rate of creatine removal was usually in the range $0 \cdot 35-0 \cdot 75 \mu \mathrm{mole} / \mathrm{mg}$. dry wt. organisms/hr. This could be increased by raising the creatine concentration (Fig. 2); in a single experiment the $K_{m}$ of creatinase was found to be $2 \cdot 3 \times 10^{-2} \mathrm{M}$. Over the range of creatine concentration tested the enzyme preparation was never more than $30 \%$ more active than the equivalent amount of whole cells acting anaerobically.

The effect of certain enzyme inhibitors was tested (Table 3). The inhibition of creatinase by $p$-chloromercuribenzoate $\left(4 \times 10^{-5} \mathrm{M}\right)$ was almost completely overcome by four times this concentration of DL-cysteine. 
Creatinase was partially purified by precipitation with $\left(\mathrm{NH}_{4}\right)_{2} \mathrm{SO}_{4}$; the fraction collected at $40-50 \%$ saturation contained the bulk of the activity. Repeated precipitation at $50 \%$ saturation caused a progressive, though variable, loss of activity amounting usually to about $70 \%$ after three precipitations.

\section{Table 3. The effect of inhibitors on the creatinase of Pseudomonas ovalis Chester}

Extract from $8 \mathrm{mg}$. acetone-dried organisms incubated at a final volume of $3 \mathrm{ml}$. in 0.067 $\mathrm{M}$-phosphate buffer $\mathrm{pH} 7 \cdot 8$ (unless otherwise stated) with creatine $(16.8 \mu \mathrm{mole}$ ) and inhibitor; controls without inhibitor. Disappearance of creatine estimated.

\begin{tabular}{lccc}
\multicolumn{1}{c}{ Inhibitor } & $\begin{array}{c}\text { Time incubated } \\
(\mathrm{hr} .)\end{array}$ & $\begin{array}{c}\text { Final concn. of } \\
\text { inhibitor } \\
(\mathrm{M})\end{array}$ & $\begin{array}{c}\text { Percentage inhibition } \\
\text { of creatine } \\
\text { removal }\end{array}$ \\
Borate, $\mathrm{pH} \mathbf{7 \cdot 8}$ & $1 \cdot 0$ & $5 \times 10^{-2}$ & 0 \\
Borate, $\mathrm{pH} \mathbf{9 \cdot 1}$ & $1 \cdot 0$ & $5 \times 10^{-2}$ & 80 \\
Azide & $2 \cdot 0$ & $2 \times 10^{-2}$ & 18 \\
Cyanide & $\mathbf{2 \cdot 0}$ & $10^{-2}$ & 0 \\
Iodoacetate & $1 \cdot 5$ & $10^{-2}$ & 20 \\
$p$-Chloromercuribenzoate & $\mathbf{2 \cdot 0}$ & $4 \times 10^{-5}$ & 100
\end{tabular}

The activity was almost completely restored by the addition of extracts from whole or acetone-dried organisms prepared by heating suspensions (30 mg. dry wt. $/ \mathrm{ml}$.) to $100^{\circ}$ for $5 \mathrm{~min}$. and centrifuging (Fig. 3). Reducing compounds such as glutathione, cysteine, mercaptoacetic acid and ascorbic acid also reactivated the enzyme either partially or completely; glutathione was the most effective, giving $90 \%$ reactivation at about $10^{-3} \mathrm{M}$ (Fig. 3 ). These

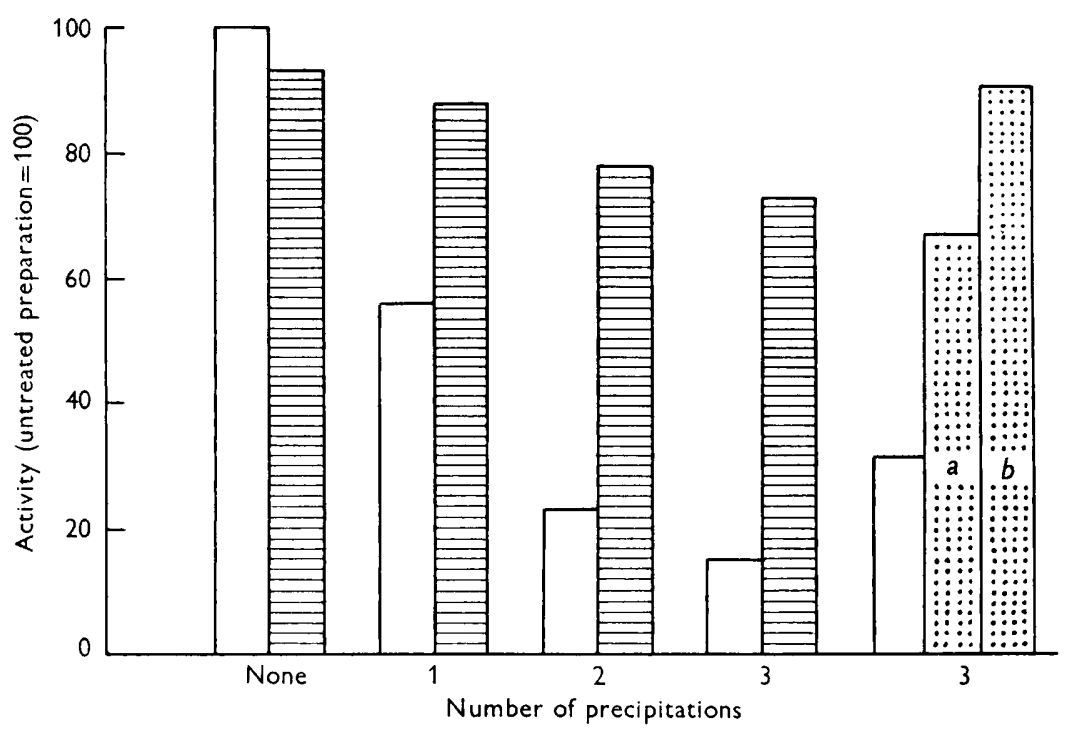

Fig. 3. Loss of creatinase activity on repeated precipitation by half-saturation with ammonium sulphate. Enzyme derived from $8 \mathrm{mg}$. acetone-dried Pseudomonas ovalis incubated in $0.067 \mathrm{M}$-phosphate buffer $\mathrm{pH} 7.8$ with $16.8 \mu$ mole creatine; total volume $3 \mathrm{ml}$. Supplements: $\square$, none; $\mathrm{Z}$, supernatant from $30 \mathrm{mg}$. heated acetone-dried organisms; 圈, reduced glutathione (a) $40 \mu$ mole, (b) 5 mmole. 
results, together with those above for $p$-chloromercuribenzoate, suggest strongly that creatinase has free thiol groups.

Creatinase could not be extracted from Pseudomonas ovalis Chester harvested from a medium containing glucose and ammonium salts in place of creatine. This confirms the previous conclusion (Nimmo-Smith \& Appleyard, 1956) that the enzyme systems metabolizing creatine are adaptive.

Action of crushed organisms. No oxygen was taken up by these preparations in the presence of creatine but, under anaerobic conditions, one molecular equivalent of urea was formed: no tests were made for sarcosine in this case. The enzyme was again soluble and present in the supernatant fluid after centrifuging the crushed material. The initial rate of removal of creatine was about $40 \%$ greater than that of the uncrushed organisms acting anaerobically. Since both whole crush and the supernatant fluid lost activity rapidly on shaking in air, this type of creatinase preparation was not further used.

Action of toluene-treated organisms. The supernatant fluid obtained by centrifuging these preparations also contained an enzyme which removed creatine with the formation of a molecular equivalent of urea. Sarcosine was detected chromatographically but was not estimated.

Aerobic production of sarcosine by whole organisms. When suspensions of these organisms oxidize relatively low concentrations of creatine $\left(6 \times 10^{-3} \mathrm{M}\right)$ the only detectable end products are urea, $\mathrm{CO}_{2}$ and $\mathrm{NH}_{3}$ (Nimmo-Smith \& Appleyard, 1956). After incubation for $1 \mathrm{hr}$. with a higher substrate concentration $\left(3 \times 10^{-2} \mathrm{M}\right)$ the presence of significant quantities of sarcosine was detected by paper chromatography; this disappeared on further incubation.

\section{The oxidation of sarcosine to glycine and formaldehyde}

The results in the preceding section suggest that the first step in the oxidation of creatine by suspensions of Pseudomonas ovalis Chester may be its hydrolysis to urea and sarcosine. If this is the case, and if it permeates the organisms, sarcosine itself should be rapidly oxidized. If sarcosine does not enter the organisms, the oxidation might be demonstrable with non-viable preparations provided that the enzyme systems are sufficiently stable.

Oxidation of sarcosine by whole organisms. Sarcosine was oxidized by suspensions of Pseudomonas ovalis under the usual conditions. As with creatine (Nimmo-Smith \& Appleyard, 1956) a definite end-point was not obtained since, after the main reaction was over (and all sarcosine had been removed), the $\mathrm{O}_{2}$ uptake continued indefinitely at slightly above the endogenous rate. Unlike creatine there was no sharp 'break' in the $\mathrm{O}_{2}$ uptake curve (Fig. 4). Approximate values for $\mathrm{O}_{2}$ and $\mathrm{NH}_{3}$ at the end of the main reaction were 1.5

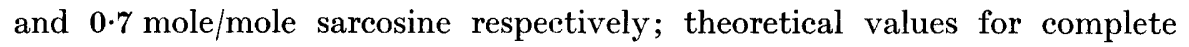
oxidation to $\mathrm{CO}_{2}$ and $\mathrm{NH}_{3}$ are $3 \cdot 0$ mole $\mathrm{O}_{2}$ and $\mathbf{1} \cdot 0$ mole $\mathrm{NH}_{3}$.

The rate of oxidation of sarcosine $\left(6 \times 10^{-3} \mathrm{M}\right)$ was only about a third of that with equimolar creatine. But as the concentration was raised the rate became equal to and finally exceeded the maximum rate obtained with creatine (Fig. 5). 
Organisms harvested from a creatine-containing medium oxidized sarcosine about twice as rapidly as those from a similar medium containing glucose and ammonium salts in place of creatine (Fig. 4). With the latter organisms there was also a short lag before the full rate was established. It appears, therefore, that the sarcosine-oxidizing enzyme systems are at least partially adaptive.

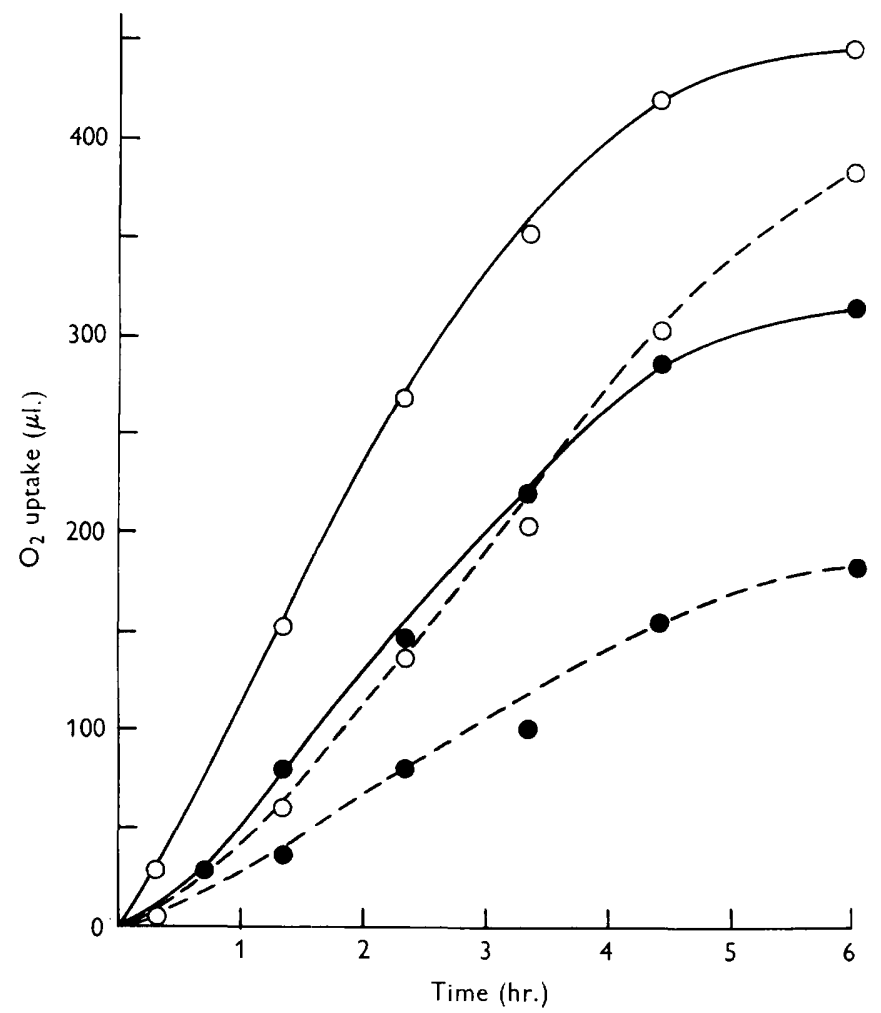

Fig. 4. Course of oxidation of sarcosine ( $\bigcirc)$ and glycine (๑) by Pseudomonas ovalis harvested from media containing creatine $(-)$ or glucose and ammonium salts $(---)$. Organisms ( $4.5 \mathrm{mg}$. dry wt.) incubated with $16.7 \mu$ mole sarcosine or glycine in $0.067 \mathrm{M}$-phosphate buffer $\mathrm{pH} 7 \cdot 8$; total volume $2.5 \mathrm{ml}$.

The action of toluene-treated organisms. Of the three types of non-viable preparations from organisms used in this work only organisms treated simply with toluene retained the power to take up $\mathrm{O}_{2}$ in the presence of creatine and sarcosine. Comparative $Q_{\mathrm{O}_{2}}$ values for whole and toluene-treated organisms showed $90 \%$ loss of activity in the case of creatine (Table 4). This may be partly explained by the loss of soluble creatinase in the supernatant fluid during the primary separation of the treated organisms from the toluenewater mixture. Centrifugation of the final preparation gave a supernatant fluid with creatinase activity, and repeated washing with water removed all such activity from the deposit, which retained, however, almost the full activity of the original preparation in oxidizing sarcosine. It is clear, therefore, 
that with toluene-treated organisms the main pathway of creatine degradation is through sarcosine as intermediate.

The $Q_{\mathrm{O}_{2}}$ with sarcosine is $60 \%$ of that given by the original organisms. Glycine is not attacked, while formaldehyde is oxidized only very slowly

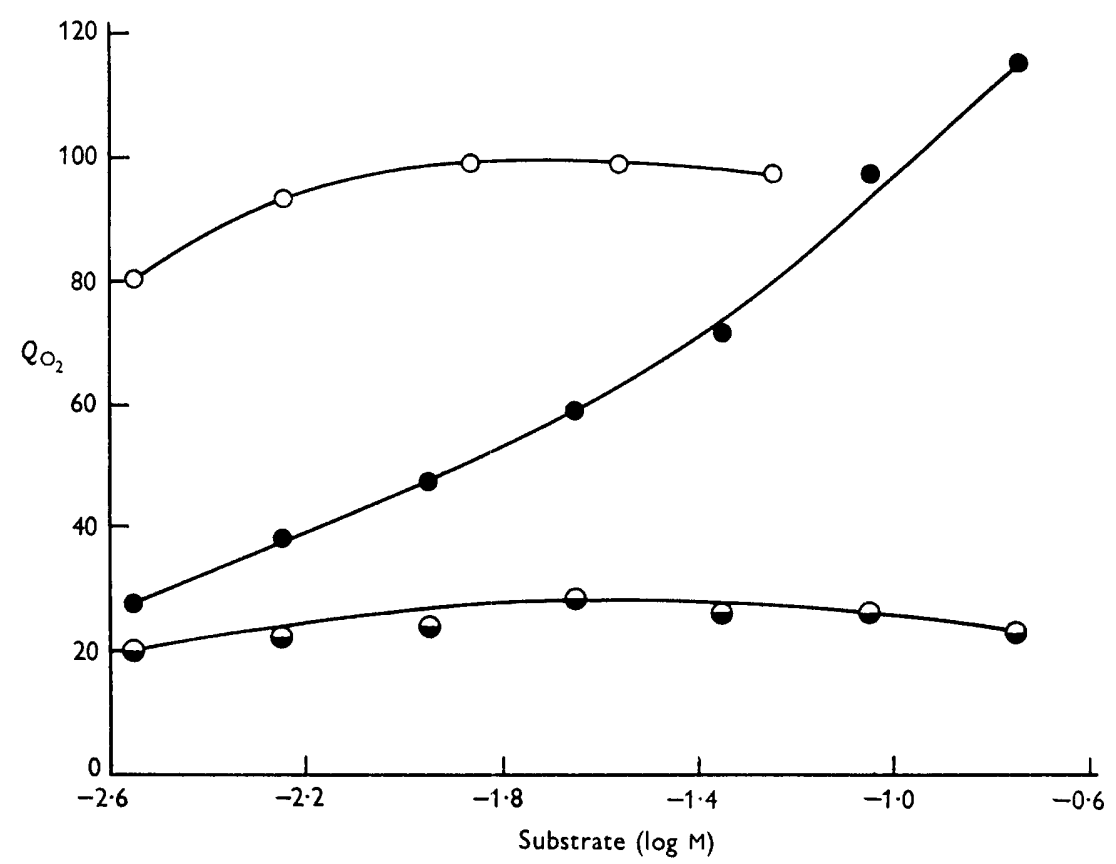

Fig. 5. Effect of substrate concentration on the rate of oxidation by cell suspensions of creatine $(O)$, sarcosine $(\bullet)$ and glycine $(\Theta)$. Organisms (4 mg. dry wt.) incubated in $0.067 \mathrm{M}$-phosphate buffer $\mathrm{pH} 7 \cdot 8$ plus substrates shown; total volume $3 \mathrm{ml}$.

Table 4. Comparative rates of oxidation of various substrates by normal and toluene-treated Pseudomonas ovalis Chester

Normal (6 mg. dry wt.) or toluene-treated (10 mg. dry wt.) organisms incubated in 0.067 M-phosphate buffer pH $7 \cdot 8$ with $16 \cdot 7 \mu$ mole substrate; total volume $3 \mathrm{ml}$.

\begin{tabular}{lcc} 
Substrate & $\begin{array}{c}\text { Normal } \\
\text { organisms } \\
\mathbf{Q}_{\mathrm{O}_{2}{ }^{*}}\end{array}$ & $\begin{array}{c}\text { Toluene-treated } \\
\text { organisms } \\
\mathbf{Q}_{\mathrm{O}_{2}}{ }^{*}\end{array}$ \\
Creatine & 100 & 9 \\
Sarcosine & 30 & 18 \\
Glycine & 20 & 0 \\
Formaldehyde & 25 & 2 \\
\hline None & $\mathbf{2 5}$ & 1
\end{tabular}

* Figures corrected for the endogenous value given in the bottom line.

(Table 4). The rate of $\mathrm{O}_{2}$ uptake with sarcosine falls to one-eighth of its original value by the time $0 \cdot 6$ mole $\mathrm{O}_{2} /$ mole sarcosine has been used and sarcosine can no longer be detected in the reaction mixture. The slower rate of $\mathrm{O}_{2}$ uptake continues indefinitely; it is probably due to the residual ability of the preparation 
to oxidize formaldehyde which is one of the products of sarcosine oxidation; formaldehyde was detected by its colour reaction with chromotropic acid (see Methods).

The presence of glycine in the reaction products was established in three ways: ( $a$ ) a ninhydrin-positive substance with an $R_{F}$ in 'phenol' similar to that of glycine was detected on paper chromatograms; it separated from added serine and threonine, but not from glycine; $(b)$ by fractionation on columns of Dowex 50; (c) by the growth response of Leuconostoc mesenteroides P60 (see Methods).

Table 5. Products of the action of toluene-treated Pseudomonas ovalis on sarcosine

Toluene-treated organisms (10 mg.) incubated in $0.08 \mathrm{~m}$-phosphate buffer pH $7 \cdot 8$ with 16.7 $\mu$ mole sarcosine; total volume $2.5 \mathrm{ml}$.

\begin{tabular}{cccc} 
& \multicolumn{3}{c}{$\mu$ mole $/ \mu$ mole sarcosine initially present } \\
Time (min.) & $\mathrm{O}_{2}$ uptake & $\begin{array}{c}\text { Formaldehyde } \\
\text { formed }\end{array}$ & $\begin{array}{c}\text { Glycine formed } \\
30\end{array}$ \\
100 & 0.18 & $0 \cdot 31$ & $0 \cdot 35$ \\
190 & 0.48 & $0 \cdot 82$ & 0.82 \\
Theoretical for & 0.58 & 0.70 & 0.98 \\
reaction (3) & 0.5 & $1 \cdot 0$ & $1 \cdot 0$
\end{tabular}

The results of quantitative experiments (Table 5) were in reasonable agreement with those expected for the reaction:

$$
\mathrm{CH}_{3} \cdot \mathrm{NH} \cdot \mathrm{CH}_{2} \cdot \mathrm{COOH}+\frac{1}{2} \mathrm{O}_{2}=\mathrm{CH}_{2} \cdot \mathrm{NH}_{2} \cdot \mathrm{COOH}+\mathrm{H} \cdot \mathrm{CHO} \text {. }
$$

By the time (190 min.) that sarcosine could no longer be detected chromatographically the $\mathrm{O}_{2}$ and formaldehyde values were respectively higher and lower than those theoretically required. This is probably accounted for by the slow oxidation of formaldehyde itself by the cell preparation; the figure for formaldehyde is actually higher at an earlier stage $(100 \mathrm{~min}$.). Some attempts to free the preparation from all ability to oxidize formaldehyde were not successful.

The enzyme catalysing reaction (3) will be termed sarcosine oxidase. It was not inhibited by $10^{-2} \mathrm{M}$-sodium azide or by $90 \%(\mathrm{v} / \mathrm{v})$ carbon monoxide in the dark; cyanide $\left(10^{-2} \mathrm{M}\right)$ inhibited completely, but was without effect at $10^{-3} \mathrm{M}$.

There was no evidence that sarcosine oxidase produced $\mathrm{H}_{2} \mathrm{O}_{2}$. The toluenetreated organisms have high catalase activity $\left(Q_{\mathrm{O}_{2}}=2500\right)$ which is abolished by sodium azide $\left(4 \times 10^{-2} \mathrm{M}\right)$. There was, however, no increased $\mathrm{O}_{2}$ uptake with sarcosine in the presence of azide and no $\mathrm{H}_{2} \mathrm{O}_{2}$ could be detected.

Aerobic production of glycine by whole organisms. Glycine was detected chromatographically during the course of the action of suspensions of organisms on either sarcosine at ten times $\left(6 \times 10^{-2} \mathrm{M}\right)$ the usual concentration or on either sarcosine or creatine $\left(6 \times 10^{-3} \mathrm{M}\right)$ in the presence of $10^{-2} \mathrm{M}$-sodium azide; this inhibitor causes a 50-60\% reduction in the rate of $\mathrm{O}_{2}$ uptake with either creatine, sarcosine or glycine. 


\section{The oxidation of glycine and formaldehyde}

Any hypothesis that the overall oxidation of creatine by whole organisms (reaction (1)) proceeds initially by the successive actions of creatinase and sarcosine oxidase (reactions (2) and (3)) demands that the organism should also contain enzymes catalysing the further oxidation of glycine and formaldehyde.

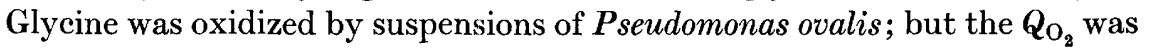
only about one-fifth of that with an equimolar concentration of creatine and did not increase appreciably when the glycine concentration was raised (Fig. 5). Quantitatively, the $\mathrm{O}_{2}$ uptake and $\mathrm{NH}_{3}$ formation fell short of the values required for complete oxidation of glycine (Table 6), but no other product was detected.

$$
\mathrm{CH}_{2} \cdot \mathrm{NH}_{2} \cdot \mathrm{COOH}+\frac{3}{2} \mathrm{O}_{2}=2 \mathrm{CO}_{2}+\mathrm{NH}_{3}+\mathrm{H}_{2} \mathrm{O} \text {. }
$$

Table 6. Oxidation of glycine and formaldehyde by suspensions of Pseudomonas ovalis

Organisms (6 mg.) incubated in $0.067 \mathrm{M}$-phosphate buffer $\mathrm{pH} 7$ with substrate as indicated; total volume $3 \mathrm{ml}$.

\begin{tabular}{|c|c|c|c|c|c|c|}
\hline \multirow[b]{3}{*}{ Substrate } & \multirow{3}{*}{$\begin{array}{c}\text { Amount } \\
(\mu \text { mole })\end{array}$} & \multirow[b]{3}{*}{$Q_{\mathrm{O}_{2}}$} & \\
\hline & & & \multicolumn{2}{|c|}{$\mathrm{O}_{2}$ uptake } & \multicolumn{2}{|c|}{$\mathrm{NH}_{3}$ formed } \\
\hline & & & Found & Theory* & Found & Theory* \\
\hline Glycine & $16 \cdot 7$ & 22 & $0 \cdot 85$ & 1.5 & 0.75 & $1 \cdot 0$ \\
\hline Formaldehyde & $8 \cdot 3 \dagger$ & 25 & $0 \cdot 6$ & $1 \cdot 0$ & - & - \\
\hline
\end{tabular}

Organisms harvested from the normal medium oxidized glycine about twice as rapidly as those from a medium in which creatine was replaced by glucose and ammonium salts (Fig. 4).

Formaldehyde was oxidized by suspensions of whole organisms ten times more rapidly than by the toluene-treated organisms (Table 4). An optimal $\mathbf{Q}_{\mathrm{O}_{2}}$ was obtained with $3 \times 10^{-3} \mathrm{M}$ substrate; above this concentration the rate fell, probably due to a toxic action of formaldehyde on the oxidative mechanisms. The total $\mathrm{O}_{2}$ uptake was only $60 \%$ of that required for complete oxidation (Table 6).

$$
\mathrm{HCHO}+\mathrm{O}_{2}=\mathrm{CO}_{2}+\mathrm{H}_{2} \mathrm{O} \text {. }
$$

\section{DISCUSSION}

It was shown in the preceding paper (Nimmo-Smith \& Appleyard, 1956) that adapted Pseudomonas ovalis Chester oxidizes creatine with the overall production of urea, $\mathrm{CO}_{2}$ and $\mathrm{NH}_{3}$. The complete oxidation of creatine (reaction (1)) would require values for $\mathrm{O}_{2}, \mathrm{CO}_{2}$ and $\mathrm{NH}_{3}$ of 3,3 and 1 mole/mole creatine respectively; approximately $1.5,1.5$ and 0.7 mole were found. This discrepancy could be only partly accounted for by concurrent oxidative assimilation 
(Clifton, 1946) of carbon and nitrogen into cell material; the highest values obtained in the presence of an uncoupling agent (sodium azide) were $2 \cdot 0, \mathbf{2} \cdot \mathbf{0}$ and 0.85 mole of $\mathrm{O}_{2}, \mathrm{CO}_{2}$ and $\mathrm{NH}_{3}$ respectively. The yield of urea was quantitative under all conditions. The fate of at least $25 \%$ of the carbon and $5 \%$ of the nitrogen of the creatine molecule is therefore unknown. Although it is possible that the extent of oxidative assimilation was greater than that demonstrated, and although no other final product was detected either by Nimmo-Smith \& Appleyard (1956) or in the present work, it is clear that discussion of the pathway of creatine oxidation must take into account the possibility that there may be another undiscovered product of the overall reaction.

The present work provides good evidence that sarcosine is an intermediate in the breakdown of the bulk of the creatine and that glycine and formaldehyde may be later intermediates in a pathway for at least part of the creatine.

Sarcosine. The evidence in favour of sarcosine as a main intermediate is $(a)$ organisms grown in media containing creatine (but not otherwise) contain an enzyme (creatinase) hydrolysing creatine to sarcosine and urea; it will be recalled that one mole of urea is invariably an end product of creatine breakdown. This enzyme can be obtained in a cell-free soluble form. (b) Sarcosine is oxidized with an uptake of $\mathrm{O}_{2}(1.5 \mathrm{~mole})$ and a production of $\mathrm{NH}_{3}(0.7$ mole $)$ similar to that found with creatine itself; this would be expected since there is neither oxidation nor deamination in the conversion of creatine to sarcosine. (c) The rate of oxidation of sarcosine is doubled by growth of the organism on a medium containing creatine. The organism also grows well on a sarcosine medium (Nimmo-Smith \& Appleyard, 1956). (d) Sarcosine can be detected during the course of creatine oxidation under certain conditions. $(e)$ The organisms also contain an enzyme, sarcosine oxidase (present also in certain nonviable preparations), which catalyses the oxidation of sarcosine to glycine, and formaldehyde.

There are, however, certain difficulties. The apparent creatinase activity of whole organisms can be measured directly under anaerobic conditions: at a substrate concentration of $6 \times 10^{-3} \mathrm{M}$ it is only one-fifth of that required to account for the aerobic removal of equimolar creatine. This does not appear to be due mainly to decreased permeability to creatine under anaerobic conditions since acetone-dried and crushed organisms are at the most $30 \%$ more active than whole organisms (Fig. 2). The difference between the anaerobic and aerobic rates of creatine removal is abolished by raising the creatine concentration tenfold (Fig. 2). If the hydrolysis of creatine is also the first stage in creatine oxidation, it is necessary to assume that under aerobic conditions the organisms are able actively to concentrate creatine internally if the external concentration is too low.

There is a similar problem with regard to the oxidation of sarcosine. Only at relatively high substrate concentrations is the $Q_{o_{2}}$ with sarcosine equal to or greater than that with equimolar creatine (Fig. 5). If sarcosine is an intermediate it is necessary to make the not unreasonable assumption that its formation within the organism produces an effective concentration in the locality of the enzyme concerned with its further metabolism. 
Glycine and formaldehyde. The position of these substances as intermediates in the oxidation of creatine by intact organisms cannot be decided on the present evidence. In favour is the fact that they are the products of a sarcosine oxidase which survives in toluene-treated organisms and that both are oxidized by untreated organisms. Furthermore, glycine can be detected during the course of oxidation of creatine and sarcosine under certain conditions (p. 361). Glycine is also oxidized more rapidly by organisms harvested from a creatine medium (Fig. 4). Even allowing for the fact that only half the $\mathrm{O}_{2}$ consumption for the complete oxidation of creatine (reaction (1)) would have to be attributed to glycine oxidation (reaction (4)), the $Q_{\mathrm{O}_{2}}$ obtained for whole organisms with glycine is only $40 \%$ of that expected if it were an intermediate. The $Q_{\mathrm{O}_{2}}$ was not increased by raising the glycine concentration (Fig. 5), and it was not possible to test if the slow rate was due to limiting permeability of exogenous glycine, since none of the non-viable preparations tried oxidized this substrate.

The total $\mathrm{O}_{2}$ uptakes with glycine and formaldehyde were less than those required for complete oxidation (Table 6 ), but no other products were detected. Oxidative assimilation with these substrates would be expected if they are intermediates; the phenomenon occurs with creatine itself and their oxidation requires five-sixths of the $\mathrm{O}_{2}$ theoretically required for complete oxidation of creatine.

On the basis of the present results it is probable that at least part of the oxidation of creatine or sarcosine proceeds through glycine when the former are present at relatively high concentrations. The possible existence of another pathway (perhaps through some derivative of glycine*) which may predominate with lower substrate concentrations cannot be excluded.

Properties of sarcosine oxidase. This enzyme has previously been found in both animal tissues and bacteria. Mammalian liver preparations oxidize sarcosine $\left(0.5\right.$ mole $\mathrm{O}_{2} /$ mole) with the production of 1 mole of an aminocompound (presumed to be glycine) and an unknown amount of formaldehyde. The enzyme was insoluble, and it was concluded that electron transfer occurred through the cytochrome system (Handler, Bernheim \& Klein, 1941; Bernheim \& Bernheim, 1942). Pseudomonas aeruginosa also contains a sarcosine oxidase whose products are glycine and formaldehyde, though these were not obtained in quantitative yield (Kopper \& Robin, 1950). This enzyme was completely inhibited by a concentration of cyanide $\left(10^{-3} \mathrm{M}\right)$ ten times less than that required with the Pseudomonas ovalis Chester enzyme. The present data are too scanty to permit a decision as to whether the cytochrome system is required for the bacterial enzyme.

This work was carried out during the tenure by one of us (G.A.) of a Medical Research Council Scholarship.

* $\mathrm{N}$-formylglycine has been prepared but was not oxidized at an appreciable rate. 


\section{REFERENCES}

APpleyard, G. (1951). The metabolism of creatine by a pseudomonad. Biochem. $J$. 49, lxx.

BEARD, H. H. (1943). The production of a creatinine oxidase and a creatine anhydrase from rat faeces. Arch. Biochem. 2, 363.

Beard, H. H. (1944). Production of a creatine-creatinine destroying enzyme from a urine mould. Arch. Biochem. 5, 293.

Bernheim, F. \& Bernheim, M. L. C. (1942). Note on the sarcosine oxidase. J. biol. Chem. 143, 391.

Clifton, C. E. (1946). Microbial assimilations. Advanc. Enzymol. 6, 269.

Curran, H. R. \& Evans, F. R. (1942). The killing of bacterial spores in fluids by agitation with small inert particles. J. Bact. 43, 125.

Dubos, R. \& Miller, B. F. (1937). The production of bacterial enzymes capable of decomposing creatinine. J. biol. Chem. 121, 429.

Eggleton, P., Elsden, S. R. \& Gough, N. (1943). The estimation of creatine and of diacetyl. Biochem. J. 37, 526 .

Handler, P., Bernheim, M. L. C. \& Kuein, J. R. (1941). The oxidative demethylation of sarcosine to glycine. J. biol. Chem. 138, 211.

Kopper, P. H. (1947). An atypical strain of Pseudomonas aeruginosa. J. Bact. 54, 359.

Kopper, P. H. (1948). A note on the component enzymes of Pseudomonas 'creatinase'. Arch. Biochem. 19, 171.

Kopper, P. H. (1950). Studies on a sarcosine oxidase of bacterial origin. J. gen. Physiol. 34, 9.

Kopper, P. H. \& Beard, H. H. (1947). Creatinase activity of a strain of Pseudomonas. Arch. Biochem. 15, 195.

Kopper, P. H. \& RoBin, L. (1950). The metabolic breakdown of sarcosine by a strain of Pseudomonas aeruginosa. Arch. Biochem. 26, 458.

Lascelles, J., Cross, M. J. \& Woons, D. D. (1954). The folic acid and serine nutrition of Leuconostoc mesenteroides $\mathrm{P} 60$ (Streptococcus equinus P60). J. gen. Microbiol. 10, 267.

Lascelles, J. \& Woods, D. D. (1954). The synthesis of serine and Leuconostoc citrovorum factor by cell suspensions of Streptococcus faecalis R. Biochem. J. 58, 486.

MACFADYEN, D. A. (1945). Estimation of formaldehyde in biological mixtures. J. biol. Chem. 158, 107.

Moore, S. \& SteIn, W. H. (1951). Chromatography of amino acids on sulfonated polystyrene resins. J. biol. Chem. 192, 663.

Nimmo-Smith, R. H. (1949). A pseudomonad capable of growing on creatine as sole source of carbon and nitrogen. Abstr. 1st Int. Congr. Biochem. p. 297.

Nimmo-Smith, R. H. \& Appleyard, G. (1956). Studies with a pseudomonad able to grow with creatine as main source of carbon and nitrogen. J. gen. Microbiol. $14,336$.

Roche, J., Girard, H., Lacombe, G. \& Mourgue, M. (1948). Sur la dégradation de la glycocyamine par Pseudomonas ovalis. Glycocyaminase et arginine dihydrolase bactériennes. Biochim. biophys. Acta, 2, 414. 